\title{
Study on the antimicrobial properties of citrate-based biodegradable polymers
}

\author{
Lee-Chun Su ${ }^{1}$, Zhiwei Xie ${ }^{2}$, Yi Zhang ${ }^{1}$, Kytai Truong Nguyen ${ }^{1}$ and Jian Yang ${ }^{2}$ * \\ ${ }^{1}$ Department of Bioengineering, University of Texas at Arlington, Arlington, TX, USA \\ 2 Department of Biomedical Engineering, Materials Research Institute, The Huck Institutes of The Life Sciences, The Pennsylvania State University, University Park, \\ PA, USA
}

\section{Edited by:}

Paul De Vos, University Medical Center Groningen, Netherlands

\section{Reviewed by:}

Igor Lacik, Polymer Institute of the

Slovak Academy of Sciences, Slovakia

Christine Wandrey, École

Polytechnique Fédérale de Lausanne, Switzerland

\section{*Correspondence:}

Kytai Truong Nguyen, Department of Bioengineering, The University of Texas at Arlington, Arlington, 76019 TX, USA

e-mail:knguyen@uta.edu;

Jian Yang, Department of Biomedical Engineering, Materials Research Institute, The Huck Institutes of The Life Sciences, The Pennsylvania State University, University Park, 16802 PA, USA

e-mail: jxy30@psu.edu
Citrate-based polymers possess unique advantages for various biomedical applications since citric acid is a natural metabolism product, which is biocompatible and antimicrobial. In polymer synthesis, citric acid also provides multiple functional groups to control the crosslinking of polymers and active binding sites for further conjugation of biomolecules. Our group recently developed a number of citrate-based polymers for various biomedical applications by taking advantage of their controllable chemical, mechanical, and biological characteristics. In this study, various citric acid derived biodegradable polymers were synthesized and investigated for their physicochemical and antimicrobial properties. Results indicate that citric acid derived polymers reduced bacterial proliferation to different degrees based on their chemical composition. Among the studied polymers, polyloctamethylene citrate) showed $\sim 70-80 \%$ suppression to microbe proliferation, owing to its relatively higher ratio of citric acid contents. Crosslinked urethane-doped polyester elastomers and biodegradable photoluminescent polymers also exhibited significant bacteria reduction of $\sim 20$ and $\sim 50 \%$ for Staphylococcus aureus and Escherichia coli, respectively. Thus, the intrinsic antibacterial properties in citrate-based polymers enable them to inhibit bacteria growth without incorporation of antibiotics, silver nanoparticles, and other traditional bacteria-killing agents suggesting that the citrate-based polymers are unique beneficial materials for wound dressing, tissue engineering, and other potential medical applications where antimicrobial property is desired.

Keywords: antimicrobial polymers, citric acid, crosslinking, biodegradable elastomers, wound dressing

\section{INTRODUCTION}

Biodegradable polymeric materials play a major role in medical and pharmaceutical domains because various biomedical devices/prostheses made with these materials have contributed enormously in human health such as tissue engineering scaffolds (Flanagan and Pandit, 2003), drug delivery systems, and wound dressings (Claudia Valenta, 2003). However, a universal challenge of applying these devices in vivo is the infection occurred by microbial-contamination. Serious infection complications include tissue destruction, premature device failure, and the spread of the infection to other areas (Woo et al., 2000). In addition, the proliferation of microorganism stimulates the cascade of body defensive responses that can be life-threatening (Christensen et al., 1990). Bacterial infection is also a major obstacle for wound healing, especially chronic wound healing (Martin, 1997). Generally, biomaterials used in Food and Drug Administration (FDA) approved wound dressings and other implants include naturally derived materials (e.g., collagen and alginate) and synthetic polymers [e.g., polylactic acid (PLA), and poly(lactic-coglycolic acid) (PLGA)]. However, these commonly used biomaterials do not possess intrinsic antibacterial properties. In recent years, tremendous efforts have been made to prevent and control biomaterials or implant related infections. However, traditional methods mostly rely on the incorporation of antimicrobial drugs/nanoparticles/peptides into the device matrix or a coating of antibiotics on the device surface with limited effectiveness (Leipziger et al., 1985; Costache et al., 2010; Wiegand et al., 2011). The main challenge is the rapid loss of antibiotics and the compromise of device or material functionalities including mechanical properties, degradation rate, and biocompatibility (Bach et al., 1994; O’Meara et al., 2000).

Recently, a series of citrate-based biodegradable polymers for tissue engineering, drug delivery, wound dressing, and bioimaging applications have been developed in our lab (Yang et al., 2004, 2009; Dey et al., 2008; Gyawali et al., 2010a; Tran et al., 2010). The essential component of these materials, citric acid (CA), is naturally contained in the body as an important intermediate in the metabolism, particularly, the tricarboxylic acid (TCA) cycle. It is also widely used as additives in foods/drinks and fillers in dental treatments (Scelza et al., 2004). In addition to its biocompatibility and hemocompatibility, citric acid is also recognized as a highly germicidal chemical (Smith and Wayman, 1986; Georgopoulou et al., 1994). The reasons may be multifaceted. CA, as an organic acid, is able to flow through the cell membranes to lower the intracellular $\mathrm{pH}$. Low $\mathrm{pH}$ within cells causes damage to enzymatic activities, protein, DNA, and extracellular membranes, thereby leading to microorganism death (Mani-López et al., 2012). Kong et al. (2001) proposed a different mechanism that organic acids such as citric acid 
can lower the $\mathrm{pH}$ and further suppress the nicotinamide adenine dinucleotide (NADH) oxidation, which results in bacteria death. Another possible reason is that citric acid alters the local $\mathrm{pH}$ environment and/or chelates the mental ions in the cell wall, which may prevent absorption of essential nutrients by the microorganisms due to the altered permeability of cell wall causing damage and hence cell death, especially in Gram-negative bacteria. Therefore, incorporating CA into biodegradable polymer chains is a rational approach to prevent microbial growth and can further promote many medical opportunities. Herein, we developed five different CA-derived polymers with various properties and investigated their antimicrobial behaviors in detail. These polymers, including poly(octamethylene citrate) (POC) (Yang et al., 2004), biodegradable photoluminescent polymer (BPLP) (Yang et al., 2009), crosslinked urethane-doped polyester elastomers (CUPE) (Dey et al., 2008), and poly(octamethylene maleate anhydride citrate) (POMC) (Tran et al., 2010), which are all biodegradable elastomers with tunable physical and mechanical properties. Due to their complete biodegradability, cytocompatibility, and versatility, they have been used for cardiac/bone tissue engineering, drug delivery, cell delivery, and medical imaging (Yang et al., 2004, 2006, 2009; Dey et al., 2008; Gyawali et al., 2010a,b; Tran et al., 2010, 2014; Guo et al., 2014; Xie et al., 2014). However, the potential risk of infection is always a concern. Unlike other biodegradable polymers like PLA and PLGA, CA-based polymers utilize CA not only as a monomer, but also as a potential antimicrobial agent. In this paper, we intend to evaluate the physical and intrinsic biocidal properties of CA polymers to explore their potential to prevent infections. The antimicrobial activities of these citric acid incorporated polymers against both Gram-positive Staphylococcus aureus (S. aureus) and Gram-negative Escherichia coli (E. coli) bacterium were studied to investigate the resistance of microbial-induced infection without incorporating antibiotics or other traditional biocidal agents.

\section{MATERIALS AND METHODS MATERIALS}

All chemicals for polymer synthesis were purchased from SigmaAldrich (Milwaukee, WI, USA) and used without further purification. E. coli (E. coli 25922) and S. aureus (S. aureus 25923) were purchased from ATCC (Manassas, VA, USA). Lysogeny Broth (LB) was purchased from Sigma-Aldrich (Milwaukee, WI, USA). Bacteriostatic Hydrofera Blue wound dressing $\left(4^{\prime \prime} \times 4^{\prime \prime}\right)$ was kindly donated by Health point (Fort Worth, TX, USA).

\section{POLYMER SYNTHESIS}

Poly(octamethylene citrate) (Yang et al., 2006), BPLP (Yang et al., 2009), CUPE (Dey et al., 2008), and POMC (Gyawali et al., 2010b;
Tran et al., 2010) were synthesized according to our previous works. Generally, citric acid and other monomers were added to a $250-\mathrm{ml}$ three-necked round bottom flask fitted with an inlet and an outlet adapter. The mixture was melted under a flow of nitrogen gas by stirring at $160-165^{\circ} \mathrm{C}$ in a silicon oil bath. The temperature of the system was subsequently lowered to $140^{\circ} \mathrm{C}$ under nitrogen purges and allowed to react to get different prepolymers. The molar ratios of citric acid to other monomers are listed in Table 1. At the end of polymerization, POC, BPLP, CUPE, and POMC pre-polymers were dissolved in 1,4-dioxane and precipitated in DI water for purification. All pre-polymers were dried by lyophilization afterward. For CUPE, an additional urethane dope process was conducted as following. The POC pre-polymer was re-dissolved to make a $3 \%(\mathrm{w} / \mathrm{w})$ solution in 1,4-dioxane, and then 1,6-hexamethylene diisocyanate (HDI) was added to the pre-polymer solution (1:0.9, citric acid:HDI molar ratio). Stannous octoate $\left[\mathrm{Sn}(\mathrm{Oct})_{2}\right]$ was used as a catalyst to activate the reaction for one week. Further, to prepare the thermal crosslinked polymer films, all pre-polymers were heated at $80^{\circ} \mathrm{C}$ for $24 \mathrm{~h}$ in Teflon molds. Photocrosslinked POMC was prepared by using Irgacure 2959 as a photo initiator and a 365-nm ultraviolet light (UVP, Upland, CA, USA) at room temperature. All CA-based polymeric scaffolds (Porosity: 90\%, pore size: 200-400 $\mu \mathrm{m}$, thickness: $2 \mathrm{~mm}$ ) were prepared via a salt-leaching method as we previously reported (Yang et al., 2004, 2006, 2009; Dey et al., 2008; Gyawali et al., 2010a; Tran et al., 2010). Representative schematics showing all synthesis procedures are presented in Figure 1.

\section{WATER UPTAKE/SWELLING}

Crosslinked polymer scaffolds prepared as above were cut into small disks and incubated in deionized water until the equilibrium state was achieved (up to $50 \mathrm{~h}$ ). At each time point, the surface of the swollen disks was gently blotted with filter paper to remove excess water. The samples were then weighed $\left(M_{\text {wet }}\right)$. The disks were again lyophilized for 3 days and weighed to determine the dry weight $\left(M_{\text {dry }}\right)$. Eq. 1 calculated the equilibrium-swelling ratio.

$$
\text { Swelling }(\%)=\frac{\left(M_{\mathrm{wet}}-M_{\mathrm{dry}}\right)}{M_{\mathrm{dry}}} \times 100
$$

\section{IN VITRO DEGRADATION}

In vitro degradation studies were conducted in $10 \mathrm{mM}$ PBS $(\mathrm{pH}$ 7.4). Six cylindrical disk specimens ( $7 \mathrm{~mm}$ in diameter; $2 \mathrm{~mm}$ in thickness) were cut from crosslinked polymer scaffolds. The samples were weighed, placed in a tube containing PBS $(10 \mathrm{ml})$ for up

Table 1 | Monomer ratios and crosslinking methods for CA based polymer synthesis and scaffold fabrication

\begin{tabular}{|c|c|c|c|c|}
\hline & $\begin{array}{l}\text { Molar ratio of } \\
\text { citric acid }\end{array}$ & $\begin{array}{l}\text { Type and molar } \\
\text { ratio of diol }\end{array}$ & $\begin{array}{l}\text { Type and molar ratio of the } \\
\text { third compound }\end{array}$ & Crosslinking method \\
\hline POC & 1.0 & 1, 8-Octanediol: 1.0 & None & Oven heating \\
\hline BPLP & 1.0 & 1, 8-Octanediol: 1.0 & L-Cysteine: 0.2 & Oven heating \\
\hline CUPE & 1.0 & 1, 8-Octanediol: 1.0 & HDI: 0.9 & Oven heating \\
\hline POMC & 0.6 & 1, 8-Octanediol: 1.0 & Maleic acid: 0.4 & Oven heating and UV exposure \\
\hline
\end{tabular}




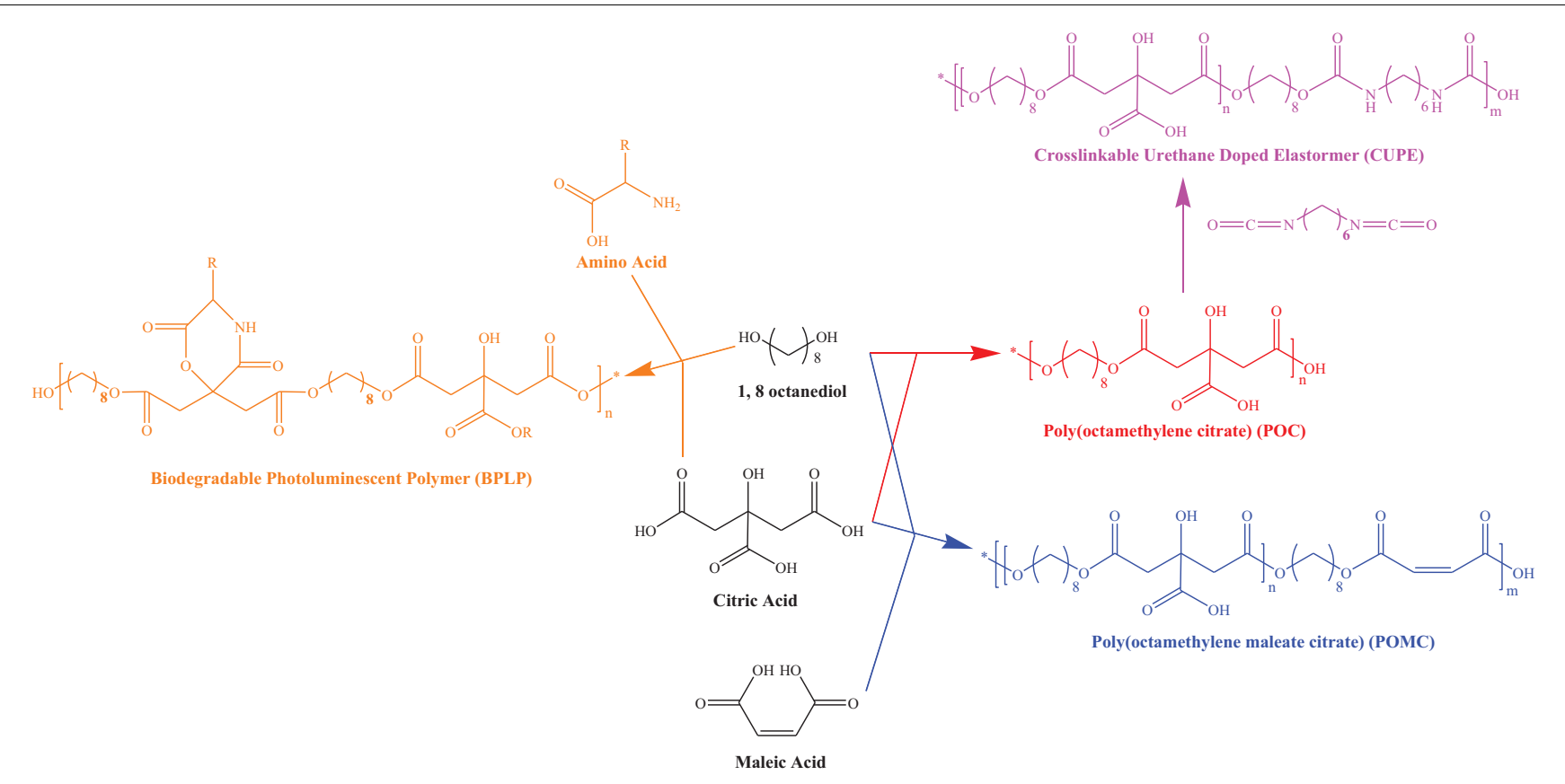

FIGURE 1 | Chemical structures and synthesis routes of citric acid based polymers including POC, BPLP, POMC, and CUPE

to 60 days at $37^{\circ} \mathrm{C}$ with shaking. At the predetermined time, samples were thoroughly washed with deionized water and lyophilized for 1 week until the weight got came to equilibrium. The mass loss was calculated by comparing the initial weight $\left(W_{0}\right)$ with the remaining weight $\left(W_{\mathrm{t}}\right)$ measured at the pre-determined time point, as shown in Eq. 2.

$$
\text { Mass remaining }(\%)=\frac{W_{\mathrm{t}}}{W_{0}} \times 100
$$

\section{MICROBIAL CULTURE AND OPTICAL DENSITY}

Gram-negative E. coli and Gram-positive S. aureus were reconstituted based on manufacturer's instructions. Briefly, $1 \mathrm{ml}$ of broth was added to rehydrate the bacterium pellet, followed by mixing a few drops of the suspension with $10 \mathrm{ml}$ broth and incubating on an orbital shaker at $37^{\circ} \mathrm{C}$ overnight for cell expansion. First, bacteria suspension with an optical density (OD) of 0.07 at $600 \mathrm{~nm}$ (measured by a UV-vis spectrophotometer), which corresponded to the approximate cell density of McFarland Standard solution \#1 $\left(3 \times 10^{8} \mathrm{CFU} / \mathrm{ml}\right)$, was prepared. Then the bacteria suspension was diluted with culture broth for 100-folds to reach the experimental concentration as previously described (Vianna et al., 2004). Dried polymer scaffold samples and Hydrofera Blue (50 mg each) were then added to $1 \mathrm{ml}$ bacterial suspension and incubated with constant shaking for $0-28 \mathrm{~h}$ at $37^{\circ} \mathrm{C}$. Scaffolds incubated with broth only were prepared as background. $2.5 \mu \mathrm{g} / \mathrm{ml}$ ampicillin and $29 \mathrm{mg} / \mathrm{ml}$ citric acid, which is the concentration of released citric acid from completely degraded $50 \mathrm{mg}$ POC (the molar ratio of CA to 1,8 -octanediol was $1: 1$ ) in $1 \mathrm{ml}$ solution, were prepared separately in broth and served as positive controls in the study. All experiments were performed in aseptic conditions.

\section{ANTIMICROBIAL ASSAY}

Citric acid polymer films were cut into round disks with $8 \mathrm{~mm}$ diameters, soaked with sterile PBS for $1 \mathrm{~h}$, and placed in 48 well plates. One milliliter LB broth was added to each well and the plates were vigorously shaken for $3 \mathrm{~min}$. Afterward, $10 \mu \mathrm{l}$ bacterial suspension was pipetted onto the disks and incubated for $24 \mathrm{~h}$ at $37^{\circ} \mathrm{C}$. Hydrofera Blue and PLGA served as positive and negative controls, respectively. Colony counting was performed according to Mygrind's method (Gottlieb et al., 2008). The antimicrobial effect of scaffolds was calculated by the percentage reduction of counted colony forming units (CFU) before and after incubation with scaffolds.

\section{MICROBIAL MORPHOLOGY OBSERVATION WITH SEM}

Ten microlilter bacterial suspensions were seeded on top of $8 \mathrm{~mm}$ diameter polymer films and incubated for $2 \mathrm{~h}$ at $37^{\circ} \mathrm{C}$. The disks were then immediately fixed with $2.5 \%$ glutaraldehyde for 20 min and washed with PBS three times. Samples were then dehydrated in a graded ethanol series $(50,75,95$, and 100\%). Finally, all samples were air-dried overnight before subjected to sputter-coating with silver and imaging by a scanning electron microscope (SEM, Hitachi S-3000N Variable Pressure, Hitachi, Pleasanton, CA, USA).

\section{STATISTICAL ANALYSIS}

All results were presented as mean $\pm \mathrm{SD}(n=6)$. All statisti$\mathrm{cal}$ analysis were performed with statistical significant of a $99 \%$ confidence interval $(p<0.01)$ using one-way ANOVA.

\section{RESULTS}

WATER UPTAKE OF CA POLYMER SCAFFOLDS

A series of CA polymers as listed in Table 1 and Figure 1 were synthesized and studied in this research. The swelling behavior 


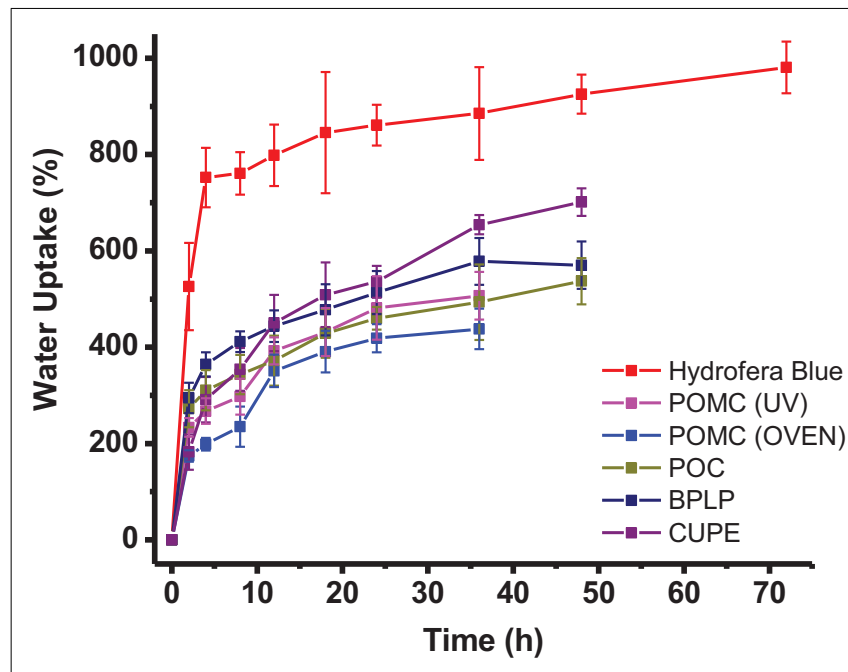

FIGURE 2 |Water uptake of crosslinked citrate-based polymers and Hydrofera Blue after different time of incubation in DI water.

of these CA-based polymers is shown in Figure 2. All polymeric scaffolds were able to uptake water, since they are crosslinked elastomers with hydrophilic carboxyl and hydroxyl functional groups. Results showed commercially available poly(vinyl alcohol) (PVA) based Hydrofera Blue had about $930 \pm 52$ wt $\%$ water uptake, which was significantly higher than CA polymers after $48 \mathrm{~h}$ incubation in DI water. The swelling ratios of CA polymers were in the range of 500-700 wt\%. Specifically, CUPE exhibited the highest average uptake at $700 \pm 20 \mathrm{wt} \%$; while POC at $535 \pm 44$ wt $\%$, and BPLP at $570 \pm 46 \mathrm{wt} \%$. In addition, UV crosslinked POMC scaffolds showed higher swelling ratios $(\sim 80 \%)$ than thermal crosslinked samples at $48 \mathrm{~h}$, suggesting a lower crosslinking density for UV crosslinking.

\section{IN VITRO DEGRADATION OF CA POLYMERS}

Degradation rates of polymers vary with chemical structures, physical morphologies, and crosslinking densities. The degradation of CA-based polymers leads to a release of free CA, which could affect the intrinsic antimicrobial properties. Thus, we further explored the degradation behaviors of different CA-based polymers. The data for in vitro degradation of CA-based polymer disks in $\mathrm{PBS}$ at $37^{\circ} \mathrm{C}$ is presented in Figure 3, which shows that all CA-based polymers are fully degradable. Differences in degradation rates can be observed among different CA polymers, mainly due to the various crosslinking degrees, rigidity, and hydrophobicity/hydrophilicity of different polymer chains. CUPE, which is an aliphatic polyester with urethane bonds doped in the polymer network, can be degraded via hydrolysis of the ester bonds (Hafeman et al., 2011). However, CUPE degrades slower (in 60 days) than other samples because strong molecular interactions among the relatively hydrophobic urethane-doped polymer chains. POC degraded faster (36 days) than the other polymers except POMC (UV crosslinked), suggesting a faster release of free citric acid. We also noticed that thermally crosslinked POMC degraded slower in PBS than UV crosslinked POMC, which degrades the fastest

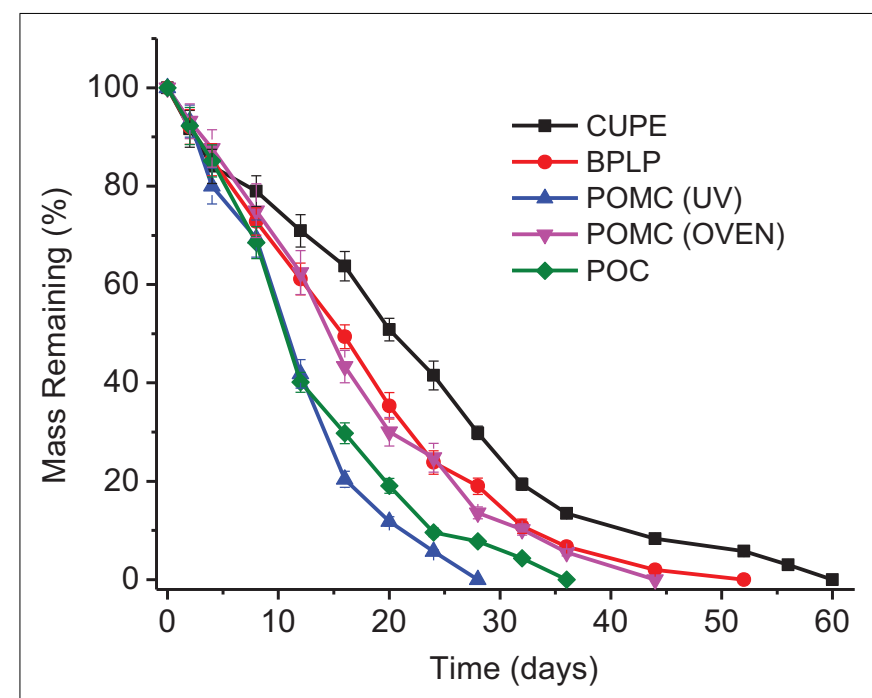

FIGURE 3 | In vitro degradation curves of citrate-based polymers in PBS until completely degraded

among all of the tested polymers. This result is consistent with the swelling data, indicating a relatively lower crosslinking density for UV crosslinking. Additionally, CA polymers displayed increasing swelling behavior with longer incubation times due to the gradual diffusion of water and the degradation of polymers introducing porosity.

\section{BACTERIA TURBIDITY}

The antimicrobial properties of polymers were evaluated against two bacterial strains, E. coli (Gram-negative) and S. aureus (Grampositive). Figures 4A,B show the OD of bacteria solutions after being treated with CA-based polymers, plus negative (bacteria/cell suspension), and positive (bacteria suspension treated antibiotic ampicillin, free citric acid solution, and commercial bacteriostatic Hydrofera Blue) controls for comparison. For both bacteria strains, POC consistently demonstrated the highest suppression of bacterial proliferation among the other CA-based polymers, whereas POMC showed relatively marginal microbial inhibition where no significant difference can be observed compared to the negative control. CUPE and BPLP performed intermediate inhibition strength against microorganisms, where the differences were still significant with around 20 and $50 \%$ reduction for E. coli and S. aureus, respectively, at day $28(p<0.01)$. In comparison, the commercially available wound dressing, Hydrofera Blue, showed no antimicrobial property at the early time points, but gradually activated its germicidal function at the late time points due to the slow release of antimicrobial dyes, methylene blue, which is incorporated within Hydrofera Blue (Shi et al., 2010). Most importantly, Figure 4 shows that the bacteria turbidity incubated with POC scaffolds reduced $68 \%$ for E. coli and $83 \%$ for S. aureus after $28 \mathrm{~h}$ of incubation compared to free bacteria control indicating that POC has similar or better bacteria-killing properties compared to that of free citric acid $(29 \mathrm{mg} / \mathrm{ml})$ and commercial Hydrofera Blue samples at late time points. 

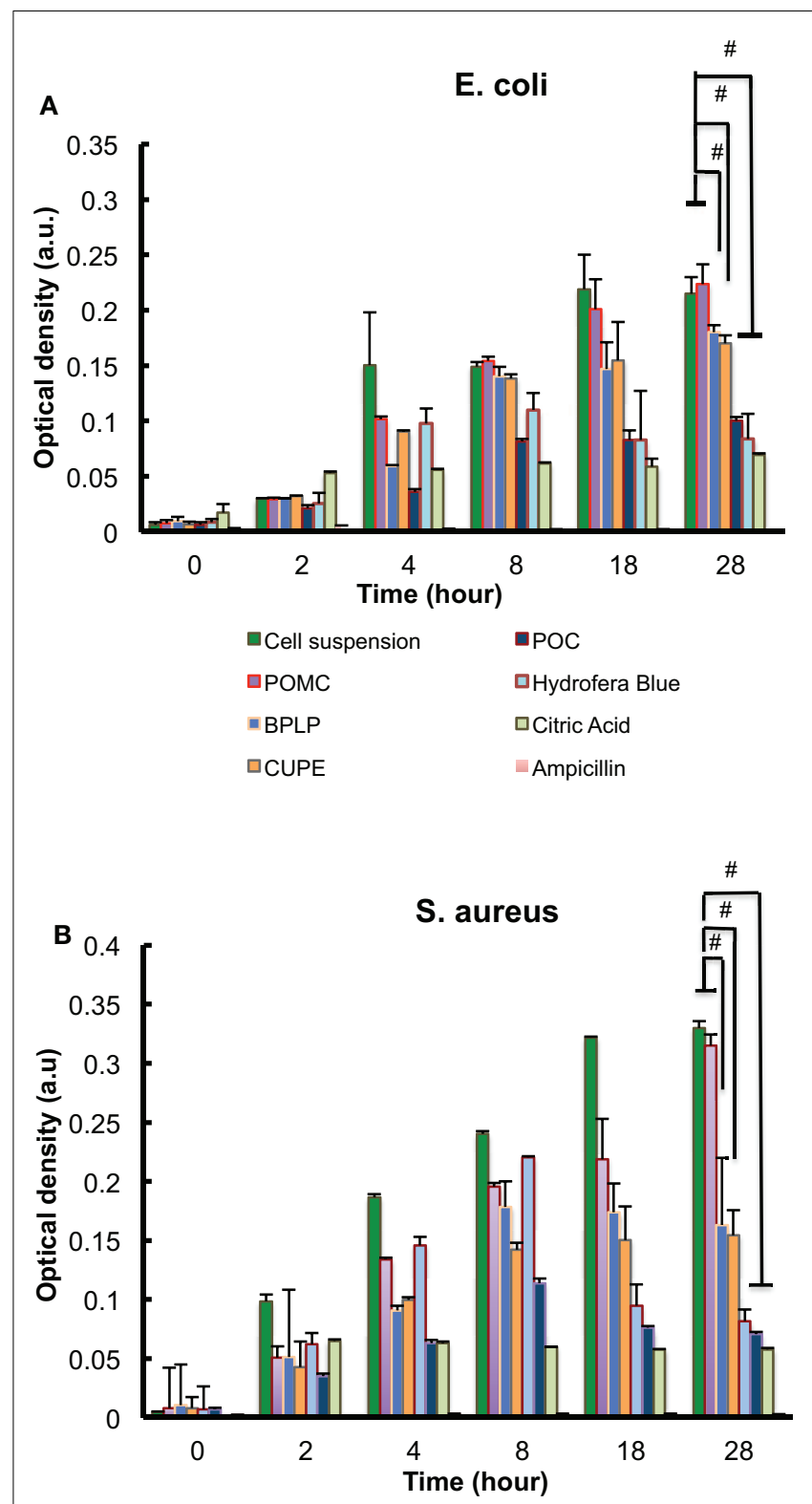

$\begin{array}{ll}\square \text { Cell suspension } & \text { 口Hydrofera Blue } \\ \text { 口POMC } & \text { घOC } \\ \text { घBPLP } & \square \text { Citric acid } \\ \square \text { CUPE } & \square \text { Ampicillin }\end{array}$

FIGURE 4 | Bacteria turbidity (optical density) studies with different citrate-based polymers (50 mg in $1 \mathrm{ml}$ solution) for $28 \mathrm{~h}$, in which $(A)$ is $\boldsymbol{E}$. coli and (B) is $\boldsymbol{S}$. aureus. Cell suspensions without any treatment are the negative controls, while free ampicillin $(2.5 \mu \mathrm{g} / \mathrm{ml})$, citric acid $(29 \mathrm{mg} / \mathrm{ml})$, and commercial bacteriostatic Hydrofera Blue $150 \mathrm{mg}$ in $1 \mathrm{ml}$ solution) are positive controls; ${ }^{\#} p<0.01$.

\section{ANTIMICROBIAL ASSAY}

The results of antimicrobial assay are presented as the percentage of reduced CFU after incubating with CA derived polymer samples (\% bacterial kill), as shown in Figure 5. Hydrofera Blue served as

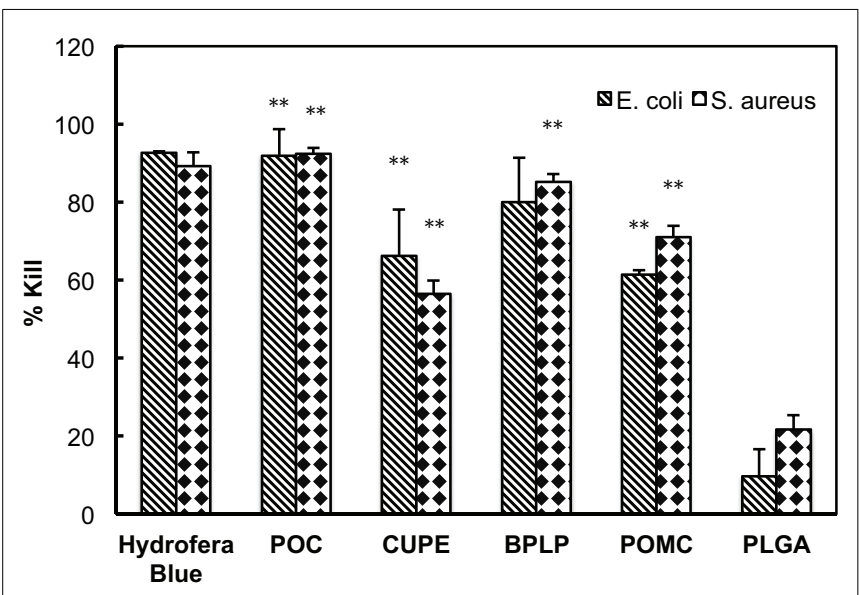

FIGURE 5 | Percentage kill of $E$. coli and $S$. aureus incubated with different CA-based polymers. The result was calculated based on reduction of CFUs before and after bacteria suspensions incubating with CA polymers. Hydrofera Blue served as the positive control and PLGA scaffolds served as the negative control; ${ }^{*} p<0.01$ comparing to PLGA group.

a positive control and a commonly used biodegradable polymer, PLGA, served as a negative control. Among all CA-based polymers, POC and BPLP had more than $80 \%$ average kill for both E. coli and S. aureus. POC showed antimicrobial effects similar to the positive control group. The \% bacterial kill of POC and BPLP is significantly higher than that of PLGA $(p<0.01)$. Subsequently, CUPE and POMC showed moderate effectiveness $(50-80 \%$ reduction with two types of bacterium); however, the differences in bacteria viability to that of PLGA are still significant $(p<0.01)$.

\section{MORPHOLOGY OF BACTERIA}

Bacteria morphology on polymer films was observed by SEM to confirm CA-based polymers' capability to inhibit bacteria growth. The representative images were taken at random positions on different polymer films with both low $(800 \times)$ and high $(4000 \times)$ magnification. Hydrofera Blue, which is a highly porous scaffold, served as the control. In case of Gram-negative E. coli, colonies mainly accumulated and aggregated at the edge of Hydrofera Blue pores. Whereas, on the surface of POC, the morphology of microbes appear relatively separated and spread with less aggregation found on center and edge areas. For Gram-positive S. aureus, we also explored similar behaviors for POC. E. coli on BPLP exhibited separated and deformed formation. However, at the edge of BPLP scaffold with S. aureus, we found a net-like pattern, indicating the beginning of biofilm formation (MacKintosh et al., 2006). Many cell aggregations were observed on both POMC and CUPE for both bacteria strains. Especially, the late stage of the E. coli biofilm appeared to be spreading on the surfaces of CUPE and POMC, suggesting their relatively weaker biocidal performance. Less cell aggregation of POC and BPLP suggested they were more effective in preventing bacteria growth.

\section{DISCUSSION}

Bacteria infection is a major medical complication that has hindered the usage of biodegradable polymers for medical 


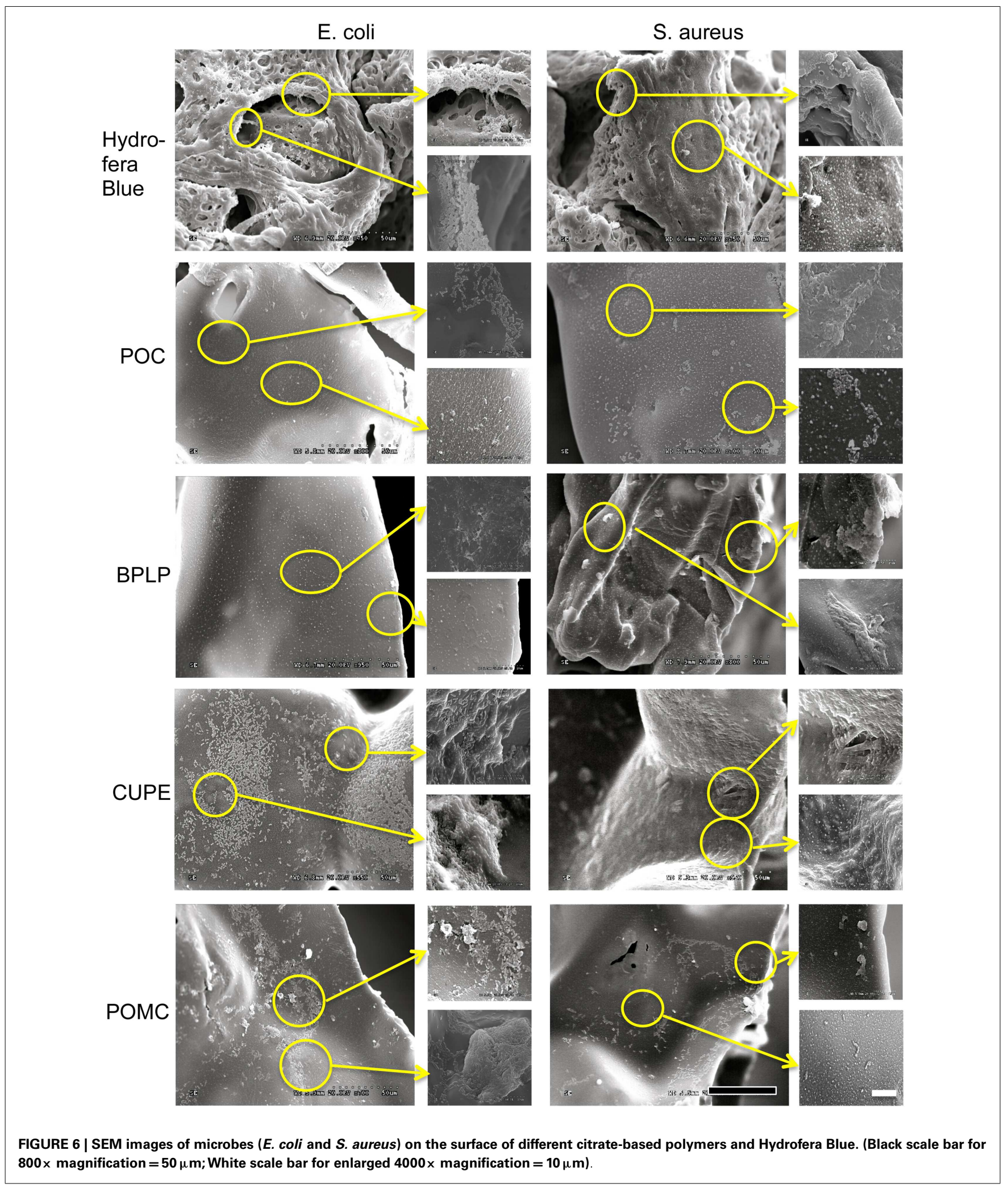

applications. Until now, traditional biodegradable polymers such as PLA, PLGA, and poly(glycerol sebacate) (PGS), cannot prevent infections by themselves. Antibiotics, nano-silver, and other chemicals are often required to be coated or encapsulated with these biodegradable polymers in order to inhibit bacteria growth. Citric acid based polymers, BPLP, CUPE, POC, and POMC, 
are emerging new biodegradable materials. Due to the antimicrobial nature of citric acid, CA-based polymers could possess intrinsic antimicrobial properties, and their microbial resistant behavior and related physical properties were investigated in this study.

Citric acid-based polymers were prepared by simple polycondensation reactions, followed by thermal crosslinking. Thus, they can degrade via the hydrolysis ester bonds that can release free citric acid, which have been confirmed in our previous studies (Serrano et al., 2011; Tran et al., 2014). Adding maleic acids to polymer backbones, POMC can also be crosslinked through free radical polymerization via UV exposure. By tuning the chemical structures of these citric-based polymers, various swelling ratios (Figure 2), and degradation rates (Figure 3 ) were presented with potentials for different tissues engineering applications. Traditional antimicrobial elastomers and gels require incorporation of antibiotics or inorganic materials like silver nanoparticles (Thomas et al., 2007; Singh et al., 2013). Thus, high swelling ratio could lead to a burst release of these bacteria-killing agents that limits the in vivo anti-infection outcomes, especially for long-term (Loke et al., 2000). CA-based elastomers and hydrogels provide unique intrinsic antimicrobial properties, thus the swelling can be tailored to meet other requirements, e.g., mechanical demands, in tissue engineering without concerns of the burst release. Also, CA-based polymers can be easily manipulated physically and mechanically. Unlike the natural antimicrobial polymers, e.g., chitosan (Zhou et al., 2009), CA polymers are advantageous due to the widely tunable material properties and functionalities for different biomedical applications.

It is well known that citric acid alone is effective for preventing bacterial growth or enhancing the antimicrobial properties of other antibiotics (Ogita et al., 2009). Allende et al. (2009) compared and concluded that E. coli proliferation was suppressed in fresh-cut cilantro after treating the cilantro with citric acid containing solution. Fu and his group mixed citric acid as crosslinker with chitosan derivatives in cotton fabrics to create antimicrobial properties. They found that $99 \%$ of $S$. aureus and $96 \%$ of $E$. coli was killed when $14 \mathrm{wt} \%$ of citric acid was used in the system (Fu et al., 2011). In this work, our investigations indicated that bacteria growth was inhibited by all CA polymers in different degrees. Particularly, POC showed to be the most effective against bacteria growth and is comparable to pure CA solutions toward killing both E. coli and S. aureus in terms of the bacteria growth inhibition. In fact, POC contains a relatively higher ratio of citric acid compared to other polymers, owing to it being composed of only two monomers (1,8-octanediol and citric acid in a 1:1 molar ratio) involved in synthesis. POC also degraded faster than other CA polymers except that POMC is UV crosslinked (Figure 3), leading to a quicker release of free citric acid, which is the active antimicrobial compound. Interestingly, after 28 days of incubation and degradation, POC exhibited similar bacteria inhibition for both E. coli and S. aureus as free citric acid with the concentration of completely degraded POC. CA, one of the organic carboxylic acids (Allende et al., 2009), contributes to local pH reduction, which may depress the internal $\mathrm{pH}$ of bacteria and/or alter the permeability of microbial membrane by disrupting their substrate transport (Kong et al., 2001; Bischof Vukusic et al., 2011; Mani-López et al., 2012). Thus, the unreacted carboxyl groups on CA-based polymers and degradation-released citric acid could be responsible for antimicrobial behaviors.

Based on the in vitro microbial morphology, four typical steps of bacterial proliferation can be observed: (1) cells adhere on material surface; (2) cells accumulate and aggregate in multiple layers; (3) biofilm formation and maturation; (4) cells detach from the biofilm to a planktonic state for a new cycle of bacterial proliferation (Mack et al., 2004). Zhou et al. (2011) described that bacteria surfaces became wrinkled and withered after incubating with their antimicrobial hydrogel coating. In addition, Otto et al. (2010) observed E. coli lyse, representing cell death, when samples were treated with mineral leachates. Our SEM images revealed various morphologies of bacterial activities on CA-based polymers. As demonstrated in Figure 6, different CA based materials showed different levels of bacterial inhibition. For example, E. coli and S. aureus tend to distribute evenly on POC and BPLP. However, cell aggregations were formed on BPLP ( $S$. aureus only), CUPE, and POMC in different degrees. Biofilms, as a later stage of bacteria growth, were found on CUPE and POMC. However, some of them showed similar bacteria morphology as commercial bacteriostatic Hydrofera Blue. Essentially, bacteria aggregated much less on POC than other CA polymer and Hydrofera Blue. This result is consistent with previous in vitro assay results. Therefore, these citric acid containing polymers surely disturbed normal microbe survival/growth patterns in different degrees.

\section{CONCLUSION}

In this study, four different biodegradable citric-based materials have been synthesized and characterized for their antimicrobial related properties. These materials can be tuned to have various physical properties including water uptake and degradation rate according to their potential applications. Among the investigated citric-acid based polymers (BPLP, CUPE, POC, and POMC), POC has the highest antimicrobial properties by taking advantage of its higher citric acid ratio and faster degradation rate, while other polymers exhibited moderate bacteria inhibition. This is the first report to systematically evaluate the antimicrobial properties of CA-based polymers without the induction of additional antibiotics, peptides, or inorganic materials, which should reaffirm the growing interests in using CA-based polymers for a number of biomedical applications, especially where antimicrobial properties are desired.

\section{ACKNOWLEDGMENTS}

This study was supported in part by the Norman Hackerman Advanced Research Program, National Institutes of Health Awards (EB012575, CA182670, and HL118498), and National Science Foundation (NSF) Awards (DMR1313553, CMMI 1266116).

\section{REFERENCES}

Allende, A., McEvoy, J., Tao, Y., and Luo, Y. (2009). Antimicrobial effect of acidified sodium chlorite, sodium chlorite, sodium hypochlorite, and citric acid on Escherichia coli $\mathrm{O} 157: \mathrm{H} 7$ and natural microflora of fresh-cut cilantro. Food Control 20, 230-234. doi:10.1016/j.foodcont.2008.05.009 
Bach, A., Bohrer, H., Motsch, J., Martin, E., Geiss, H. K., and Sonntag, H. G. (1994). Prevention of bacterial colonization of intravenous catheters by antiseptic impregnation of polyurethane polymers. J. Antimicrob. Chemother. 33, 969-978. doi:10.1093/jac/33.5.969

Bischof Vukusic, S., Flincec Grgac, S., Budimir, A., and Kalenic, S. (2011). Cotton textiles modified with citric acid as efficient anti-bacterial agent for prevention of nosocomial infections. Croat. Med. J. 52, 68-75. doi:10.3325/cmj.2011.52.68

Christensen, G. D., Barker, L. P., Mawhinney, T. P., Baddour, L. M., and Simpson, W. A. (1990). Identification of an antigenic marker of slime production for Staphylococcus epidermidis. Infect. Immun. 58, 2906-2911.

Claudia Valenta, B. G. A. (2003). The use of polymers for dermal and transdermal delivery. Eur. J. Pharm. Biopharm. 58, 279-289. doi:10.1016/j.ejpb.2004.02.017

Costache, M. C., Qu, H., Ducheyne, P., and Devore, D. I. (2010). Polymer-xerogel composites for controlled release wound dressings. Biomaterials 31, 6336-6343. doi:10.1016/j.biomaterials.2010.04.065

Dey, J., Xu, H., Shen, J., Thevenot, P., Gondi, S. R., Nguyen, K. T., et al. (2008). Development of biodegradable crosslinked urethane-doped polyester elastomers. Biomaterials 29, 4637-4649. doi:10.1016/j.biomaterials.2008.08.020

Flanagan, T. C., and Pandit, A. (2003). Living artificial heart valve alternatives: a review. Eur. Cell. Mater. 6, 28-45.

Fu, X., Shen, Y., Shen, X., Jiang, X., Huang, D., and Yan, Y. (2011). Chitosan derivatives with dual-antibacterial functional groups for antimicrobial finishing of cotton fabrics. Carbohydr. Polym. 85, 221-227. doi:10.1016/j.carbpol.2011.02.019

Georgopoulou, M., Kontakiotis, E., and Nakou, M. (1994). Evaluation of the antimicrobial effectiveness of citric acid and sodium hypochlorite on the anaerobic flora of the infected root canal. Int. Endod. J. 27, 139-143. doi:10.1111/j.1365-2591. 1994.tb00243.x

Gottlieb, C. T., Thomsen, L. E., Ingmer, H., Mygind, P. H., Kristensen, H. H., and Gram, L. (2008). Antimicrobial peptides effectively kill a broad spectrum of Listeria monocytogenes and Staphylococcus aureus strains independently of origin, sub-type, or virulence factor expression. BMC Microbiol. 8:205. doi:10.1186/1471-2180-8-205

Guo, J., Xie, Z., Tran, R. T., Xie, D., Jin, D., Bai, X., et al. (2014). Click chemistry plays a dual role in biodegradable polymer design. Adv. Mater. Weinheim 26, 1906-1911. doi:10.1002/adma.201305162

Gyawali, D., Nair, P., Zhang, Y., Tran, R. T., Zhang, C., Samchukov, M., et al. (2010a). Citric acid-derived in situ crosslinkable biodegradable polymers for cell delivery. Biomaterials 31, 9092-9105. doi:10.1016/j.biomaterials.2010.08.022

Gyawali, D., Tran, R. T., Guleserian, K. J., Tang, L., and Yang, J. (2010b). Citric-acidderived photo-cross-linked biodegradable elastomers. J. Biomater. Sci. Polym. Ed. 21, 1761-1782. doi:10.1163/092050609X12567178204169

Hafeman, A. E., Zienkiewicz, K. J., Zachman, A. L., Sung, H.-J., Nanney, L. B., Davidson, J. M., et al. (2011). Characterization of the degradation mechanisms of lysine-derived aliphatic poly(ester urethane) scaffolds. Biomaterials 32, 419-429. doi:10.1016/j.biomaterials.2010.08.108

Kong, Y.-J., Park, B.-K., and Oh, D.-H. (2001). Antimicrobial activity of Quercus mongolica leaf ethanol extract and organic acids against food-borne microorganisms. Korean J. Food Sci. Technol. 33, 178-183.

Leipziger, L. S., Glushko, V., DiBernardo, B., Shafaie, F., Noble, J., Nichols, J., et al. (1985). Dermal wound repair: role of collagen matrix implants and synthetic polymer dressings. J. Am. Acad. Dermatol. 12, 409-419. doi:10.1016/S01909622(85)80004-9

Loke, W.-K., Lau, S.-K., Yong, L. L., Khor, E., and Sum, C. K. (2000). Wound dressing with sustained anti-microbial capability. J. Biomed. Mater. Res. 53, 8-17. doi:10.1002/(SICI)1097-4636(2000)53:1<8::AID-JBM2>3.3.CO;2-V

Mack, D., Becker, P., Chatterjee, I., Dobinsky, S., Knobloch, J. K., Peters, G., et al. (2004). Mechanisms of biofilm formation in Staphylococcus epidermidis and Staphylococcus aureus: functional molecules, regulatory circuits, and adaptive responses. Int. J. Med. Microbiol. 294, 203-212. doi:10.1016/j.ijmm.2004.06.015

MacKintosh, E. E., Patel, J. D., Marchant, R. E., and Anderson, J. M. (2006). Effects of biomaterial surface chemistry on the adhesion and biofilm formation of Staphylococcus epidermidis in vitro. J. Biomed. Mater. Res. A 78A, 836-842. doi:10.1002/jbm.a.30905

Mani-López, E., García, H. S., and López-Malo, A. (2012). Organic acids as antimicrobials to control Salmonella in meat and poultry products. Food Res. Intern. 45, 713-721. doi:10.1080/03079457.2013.782097

Martin, P. (1997). Wound healing - aiming for perfect skin regeneration. Science 276, 75-81. doi:10.1126/science.276.5309.75
Ogita, A., Fujita, K.-I., and Tanaka, T. (2009). Salinomycin and citric acid in combination demonstrate bactericidal activity against Gram-negative bacteria. Ann. Microbiol. 59, 611-614. doi:10.1007/BF03175153

O’Meara, S., Cullum, N., Majid, M., and Sheldon, T. (2000). Systematic reviews of wound care management: (3) antimicrobial agents for chronic wounds; (4) diabetic foot ulceration. Health Technol. Assess. 4, 1-237.

Otto, C. C., Cunningham, T. M., Hansen, M. R., and Haydel, S. E. (2010). Effects of antibacterial mineral leachates on the cellular ultrastructure, morphology, and membrane integrity of Escherichia coli and methicillin-resistant Staphylococcus aureus. Ann. Clin. Microbiol. Antimicrob. 9, 26. doi:10.1186/14760711-9-26

Scelza, M. F., Pierro, V., Scelza, P., and Pereira, M. (2004). Effect of three different time periods of irrigation with EDTA-T, EDTA, and citric acid on smear layer removal. Oral Surg. Oral Med. Oral Pathol. Oral Radiol. Endod. 98, 499-503. doi:10.1016/j.tripleo.2004.03.027

Serrano, C. A., Zhang, Y., Yang, J., and Schug, K. A. (2011). Matrix-assisted laser desorption/ionization mass spectrometric analysis of aliphatic biodegradable photoluminescent polymers using new ionic liquid matrices. Rapid Commun. Mass Spectrom. 25, 1152-1158. doi:10.1002/rcm.4974

Shi, L., Ermis, R., Kiedaisch, B., and Carson, D. (2010). The effect of various wound dressings on the activity of debriding enzymes. Adv. Skin Wound Care 23, 456-462. doi:10.1097/01.ASW.0000383224.64524.ae

Singh, B., Sharma, S., and Dhiman, A. (2013). Design of antibiotic containing hydrogel wound dressings: biomedical properties and histological study of wound healing. Int. J. Pharm. 457, 82-91. doi:10.1016/j.ijpharm.2013.09.028

Smith, J. J., and Wayman, B. E. (1986). An evaluation of the antimicrobial effectiveness of citric acid as a root canal irrigant. J. Endod. 12, 54-58. doi:10.1016/ S0099-2399(86)80128-5

Thomas, V., Yallapu, M. M., Sreedhar, B., and Bajpai, S. K. (2007). A versatile strategy to fabricate hydrogel-silver nanocomposites and investigation of their antimicrobial activity. J. Colloid Interface Sci. 315, 389-395. doi:10.1016/j.jcis. 2007.06.068

Tran, R. T., Thevenot, P., Gyawali, D., Chiao, J. C., Tang, L., and Yang, J. (2010). Synthesis and characterization of a biodegradable elastomer featuring a dual crosslinking mechanism. Soft Matter 6, 2449-2461. doi:10.1039/c001605e

Tran, R. T., Wang, L., Zhang, C., Huang, M., Tang, W., Zhang, C., et al. (2014). Synthesis and characterization of biomimetic citrate-based biodegradable composites. J. Biomed. Mater. Res. A 102, 2521-2532. doi:10.1002/jbm.a.34928

Vianna, M. E., Gomesc, B. P. F. A., Berber, V. B., Zaia, A. A., Ferraz, C. C. R., and Souza-Filho, F. J. D. (2004). In vitro evaluation of the antimicrobial activity of chlorhexidine and sodium hypochlorite. Oral Surg. Oral Med. Oral Pathol. Oral Radiol. Endod. 97, 79-84. doi:10.1016/S1079-2104(03)00360-3

Wiegand, C., Abel, M., Ruth, P., and Hipler, U. C. (2011). Superabsorbent polymercontaining wound dressings have a beneficial effect on wound healing by reducing PMN elastase concentration and inhibiting microbial growth. J. Mater. Sci. Mater. Med. 22, 2583-2590. doi:10.1007/s10856-011-4423-3

Woo, G. L., Mittelman, M. W., and Santerre, J. P. (2000). Synthesis and characterization of a novel biodegradable antimicrobial polymer. Biomaterials 21, 1235-1246. doi:10.1016/S0142-9612(00)00003-X

Xie, Z., Zhang, Y., Liu, L., Weng, H., Mason, R. P., Tang, L., et al. (2014). Development of intrinsically photoluminescent and photostable polylactones. Adv. Mater. doi:10.1002/adma.201306070

Yang, J., Webb, A. R., and Ameer, G. A. (2004). Novel citric acid-based biodegradable elastomers for tissue engineering. Adv. Mater. 16, 511-516. doi:10.1002/adma. 200306264

Yang, J., Webb, A. R., Pickerill, S. J., Hageman, G., and Ameer, G. A. (2006). Synthesis and evaluation of poly(diol citrate) biodegradable elastomers. Biomaterials 27, 1889-1898. doi:10.1016/j.biomaterials.2005.05.106

Yang, J., Zhang, Y., Gautam, S., Liu, L., Dey, J., Chen, W., et al. (2009). Development of aliphatic biodegradable photoluminescent polymers. Proc. Natl. Acad. Sci. U.S.A. 106, 10086-10091. doi:10.1073/pnas.0900004106

Zhou, C., Li, P., Qi, X., Sharif, A. R., Poon, Y. F., Cao, Y., et al. (2011). A photopolymerized antimicrobial hydrogel coating derived from epsilon-poly-L-lysine. Biomaterials 32, 2704-2712. doi:10.1016/j.biomaterials.2010.12.040

Zhou, Y., Yang, D., Gao, X., Chen, X., Xu, Q., Lu, F., et al. (2009). Semiinterpenetrating polymer network hydrogels based on water-soluble $\mathrm{N}$ carboxylethyl chitosan and photopolymerized poly (2-hydroxyethyl methacrylate). Carbohydr. Polym. 75, 293-298. doi:10.1016/j.carbpol.2008.07.024 
Conflict of Interest Statement: The authors declare that the research was conducted in the absence of any commercial or financial relationships that could be construed as a potential conflict of interest.

Received: 02 May 2014; accepted: 17 June 2014; published online: 03 July 2014. Citation: Su L-C, Xie Z, Zhang Y, Nguyen KT and Yang J (2014) Study on the antimicrobial properties of citrate-based biodegradable polymers. Front. Bioeng. Biotechnol. 2:23. doi: 10.3389/fbioe.2014.00023
This article was submitted to Biomaterials, a section of the journal Frontiers in Bioengineering and Biotechnology.

Copyright (C) 2014 Su, Xie, Zhang, Nguyen and Yang. This is an open-access article distributed under the terms of the Creative Commons Attribution License (CC BY). The use, distribution or reproduction in other forums is permitted, provided the original author(s) or licensor are credited and that the original publication in this journal is cited, in accordance with accepted academic practice. No use, distribution or reproduction is permitted which does not comply with these terms. 